\title{
Sleep Disorders in Children of Zanjan City (Northwest, Iran) Kindergartens
}

\author{
Zohre Torabi $^{1 \text { (D) }}$,Afshin Mansouri ${ }^{2, \text { iD }}$, Alireza Armani ${ }^{3 *(D)}$, Hamid Khederlou $^{4 *(i D}$ \\ 1. Dept. of Pediatrics, Mousavi Hospital, Zanjan University of Medical Sciences, Zanjan, Iran \\ 2. Mousavi Hospital, Zanjan University of Medical Sciences, Zanjan, Iran \\ 3. Dept. of Psychiatrist, Beheshti Hospital, Zanjan University of Medical Sciences, Zanjan, Iran \\ 4. Student Research Center, Zanjan University of Medical Sciences, Zanjan, Iran
}

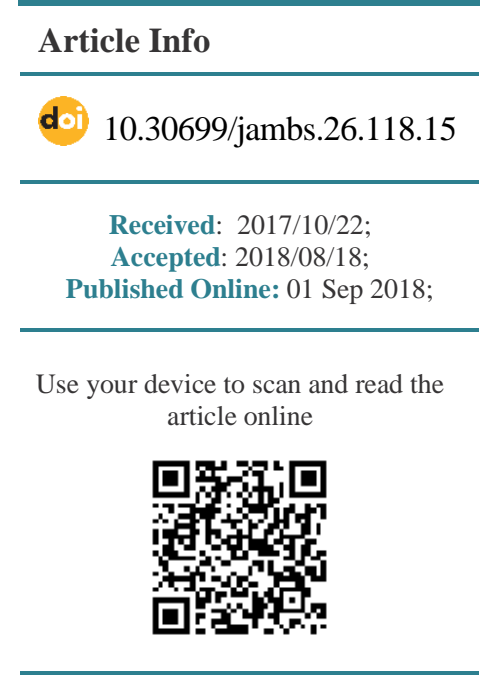

Corresponding Information: Hamid Khederlou,

Student Research Center, Zanjan

University of Medical Sciences, Zanjan,

Iran Email: ham_khed@yahoo.com

\begin{abstract}
Background \& Objective: Sleep behaviors have a significant impact on a child's quality of life; thus, sleep disorders are a major concern for parents. These disorders show the highest prevalence amongst pre-school children which can lead to mood disorders and disruption of cognitive and emotional abilities. These side effects can subsequently cause failure in school, family problems and psychiatric disorders.
\end{abstract}

Materials \& Methods: Primarily, a list of kindergartens located in Zanjan city were selected with the help of the State Welfare Organization of Iran. The cluster sampling method was used and 345 samples were randomly entered to the study. Parents were asked to respond to the researcher's questions based on BEARS questionnaire. Finally, the data were analyzed using SPSS software.

Results: 304 of 345 children participating in the study (88\%) had sleep disorders. Fear of sleeping alone was the most reported sleep disorders $(59.4 \%)$. Our study showed that the use of mass media reduced sleep-related problems $(P=0.027)$. There was a significant association between maternal education and sleep disorders, and the lowest prevalence of sleep disorders was observed amongst children whose mothers held a bachelor's degree $(P=0.008)$.

Conclusion: The high prevalence of sleep disorders in this study suggests that such psychological problems require special attention by pediatricians, pediatric psychiatrists and general health professionals with an orientation towards teamwork.

Keywords: Sleep wake disorders, Child, Preschool, Iran

\section{Introduction}

Sleep plays an important role in physical and mental health, growth and daily activities of children (1). Sleep disorders occur during NREM (Non-Rapid Eye Movement) sleep and are more frequent in the early hours of sleep with the highest prevalence among preschool children (2).

In a general classification, sleep disorders are divided into sleep-related diseases and sleep problems. Sleeprelated diseases including obstructive airway disease, narcolepsy and insomnia. Sleep problems include maintenance of an appropriate bedtime, somnambulism, sleep deprivation and sleep-related anxiety (3). Sleep behaviors of children have an important influence on their quality of life (4), and sleep-related disorders, including inadequate and interrupted sleep, as well as associated mood and behavioral disorders, are amongst the main concerns of parents (5). 25-30\% of children experience sleep disorders regardless of age (6), which can be seen as the most common complaint in pediatric medicine $(2,7)$.
A sleep disorder first appears in the form of mood disorder (8). However, the most obvious and serious complication associated with childhood sleep disorders is disruption of cognitive abilities and emotional regulations, which results in the risk of school failure, family problems and psychiatric disorders $(2,9)$.

The diagnosis of sleep disorders is a clinical matter (10). Some studies have shown that primary care physicians in children have little knowledge of sleep disorders (11), which results in poor management and improper treatment of sleep disorders and its related outcomes such as emotional, behavioral, and cognitive disorders $(12,13)$. Therefore, the screening of sleep disorders should be considered important for health providers (4). A formula for healthy sleep habits and Behavioral effects is the cornerstone for the prevention and treatment of sleep disorders (2), which requires awareness of the prevalence of sleep disorders and the factors affecting it. The aim of this study was to investigate the prevalence of sleep disorders amongst 
preschool children, in order to encourage more awareness and attention on this matter to parents and health care providers.

\section{Materials and Methods}

This was a cross-sectional descriptive study on children aged 2-5 years in the kindergartens of Zanjan in 2016.

\section{Sampling Method}

The health of children regarding growth and development was considered as the inclusion criteria but the developmental problems such as mental retardation, cerebral palsy, psychosis, hyperactivity, autism and single parenting were regarded as the exclusion criterion. In this study, the cluster sampling method was used, with a study sample size of 345 by applying the cluster coefficient of 1.5 .

\section{Data Collection Tool}

Initially, a permission was obtained from the Ethics Committee (ZUMS.REC.1393.79 ethics code). Then after explaining the importance of the subject to parents and kindergarten authorities, they were asked to accurately respond to BEARS questionnaire. A written informed consent was obtained from all participants' legal guardians. The questionnaire consisted of two parts. The first part of the questionnaire was approved by two pediatricians, a psychiatrist, and a social medicine specialist. The first part included demographic information, social and economic family status, leisure time, mass media (a tool used in a society for communicating messages, expressing thoughts and transferring concepts to others such as radio, television, press, cinema, satellite dishes, computer and video) and dietary habits of children (child's reaction to nutritional preferences in terms of type, volume and variety of food) (14). The second part was a Persian translation of BEARS questionnaire verified for reliability and validity (15), including options such as: difficulty of going to bed (insomnia), fatigue and drowsiness throughout the day, frequent disruption of night sleep, order of waking and sleeping and snoring.

\section{Method of Questionnaire Validity and Reliability Determination}

Internal consistency of the questionnaire was calculated in a pilot study of 30 samples using Cranach's alpha (0.44). The reliability of the study was calculated using test-retest for each item in the questionnaire, and the correlation coefficient for all items was calculated as 0.7 .

\section{Data Analysis Method}

Chi-square test was used to determine the relationship between anthropometric characteristics and sleep problems. Data was analyzed using SPSS 19 (SPSS Inc., Chicago, Ill., USA) with a significant level of 0.05

\section{Results}

Out of the 345 children under study, 304 (88.1\%) had sleep disorders. 87 subjects $(25.3 \%)$ had at least one sleep disorder and one subject $(0.3 \%)$ had all ten sleep disorders

According to BEARS questionnaire, fear of sleeping alone $(59.4 \%)$, improper timing of sleeping and waking $(44.4 \%)$ as well as disorders with bedtime $(30.4 \%)$ were the most common sleep disorders among children (Table 1).

Table1. Frequency and prevalence of sleep disorders based on BEARS questionnaire

\begin{tabular}{|c|c|c|}
\hline Sleep Disorders & \multicolumn{2}{|c|}{ Frequency $(\%)$} \\
\hline & Yes & No \\
\hline Waking up horrified & (12.2) 42 & (87.7) 303 \\
\hline Sleep talking & (21.4) 74 & (78.6) 271 \\
\hline Teeth grinding & (11.9) 41 & (1.88) 304 \\
\hline Fear of sleeping alone & (59.4) 205 & (40.6) 140 \\
\hline Problem with bedtime & (30.4) 105 & (69.6) 240 \\
\hline Difficulty falling sleep & (19.1) 66 & 279 \\
\hline Daytime drowsiness & (14.2) 49 & (85.4) 296 \\
\hline $\begin{array}{l}\text { Improper sleeping and } \\
\text { waking time }\end{array}$ & (44.4) 153 & (55.6) 192 \\
\hline Snoring & (8.7) 30 & (91.3) 315 \\
\hline Waking during night sleep & (13.9) 48 & (86.1) 297 \\
\hline
\end{tabular}

The subjects included 158 girls and 187 boys amongst whom $88.87 \%$ and $87.7 \%$ had at least one sleep disorder, respectively. Most children under study were three years old. The highest prevalence of sleep disorders was observed amongst two-year-olds. There was no significant association between sleep disorders and age $(P=0.412)$ nor between sleep disorders and gender $(P=0.473)$ (Table 2$)$.

Sixty percent of the children under study were firstborns, 34\% were the second-borns and $6 \%$ were third-borns in their families, and $91 \%$ of the firstborns, $84 \%$ of the second-borns and $89.9 \%$ of the third-borns had sleep disorders. There was no significant relationship between sleep disorders and a child's rank in their family (firstborns, second-borns or third-borns) $(P=0.061)$, nor between sleep disorders and the number of siblings $(P=0.096)$. 
Table 2. Frequency of sleep disorders in subjects by gender and age

\begin{tabular}{|c|c|c|c|c|}
\hline Variable & Number & Sleep disorders & Frequency (\%) & P-Value \\
\hline \multicolumn{5}{|l|}{ Gender } \\
\hline \multicolumn{4}{|c|}{ No } & \multirow{7}{*}{0.473} \\
\hline Female & 158 & 1 & $19(12.02)$ & \\
\hline & & $2 \geq$ & $38(24.05)$ & \\
\hline & & No & $101(63.90)$ & \\
\hline \multirow[t]{2}{*}{ Male } & 187 & 1 & $23(12.30)$ & \\
\hline & & $2 \geq$ & $49(26.20)$ & \\
\hline \multirow[t]{2}{*}{ Age } & & & $115(61.50)$ & \\
\hline & \multicolumn{3}{|c|}{ No } & \multirow{11}{*}{0.412} \\
\hline years2 & 57 & 1 & $5(8.70)$ & \\
\hline & & $2 \geq$ & $16(28.07)$ & \\
\hline & & No & $36(1.63)$ & \\
\hline \multirow[t]{3}{*}{3 years } & 99 & 1 & $13(13.10)$ & \\
\hline & & $2 \geq$ & $28(28.30)$ & \\
\hline & & No & $58(58.60)$ & \\
\hline \multirow[t]{3}{*}{4 years } & 98 & 1 & $17(17.30)$ & \\
\hline & & $2 \geq$ & $18(18.40)$ & \\
\hline & & No & $63(64.30)$ & \\
\hline 5 years & 91 & 1 & $7(7.70)$ & \\
\hline
\end{tabular}

Table 3. The frequency of sleep disorders based on the use of mass media and dietary habits

\begin{tabular}{|c|c|c|c|c|}
\hline Variable & Number & Sleep Disorders & Frequency (\%) & P-Value \\
\hline \multicolumn{5}{|l|}{ Mass media } \\
\hline \multirow{2}{*}{ Non-users } & \multirow{2}{*}{70} & No & $10(3.14)$ & \multirow{4}{*}{0.027} \\
\hline & & Yes & $60(7.85)$ & \\
\hline \multirow{2}{*}{ users } & \multirow{2}{*}{275} & No & $11(4)$ & \\
\hline & & Yes & $264(96)$ & \\
\hline \multicolumn{5}{|c|}{ Dietary behavior } \\
\hline \multirow{2}{*}{ Inappropriate } & \multirow{2}{*}{66} & No & $5(7.6)$ & \multirow{6}{*}{0.226} \\
\hline & & Yes & $61(92.40)$ & \\
\hline \multirow{2}{*}{ Acceptable } & \multirow{2}{*}{219} & No & $28(12.80)$ & \\
\hline & & Yes & $191(87.20)$ & \\
\hline \multirow{2}{*}{ Proper } & \multirow{2}{*}{59} & No & $8(13.60)$ & \\
\hline & & Yes & $51(86.40)$ & \\
\hline
\end{tabular}

Parent's education and its relationship with the prevalence of childhood sleep disorders was also studied. The majority of children had parents with a bachelor's degree. There was no significant relationship between sleep disorders and maternal occupation $(P=0.191)$; however, there was a significant relationship between maternal education and sleep disorders $(P=0.008)$. The lowest prevalence of sleep disorders was seen among children whose mothers had a bachelor's degree and the highest prevalence seen among children whose mothers had a graduate or postgraduate education. No significant relationship was found between a father's education and sleep disorders $(P=0.226)$ (Table 4). 
Table 4. Frequency of sleep disorders based on maternal education and occupation

\begin{tabular}{|c|c|c|c|c|}
\hline Variable & Number & Sleep disorders & Frequency $(\%)$ & P-Value \\
\hline \multicolumn{5}{|l|}{ Education } \\
\hline \multirow{2}{*}{ Below a High School Diploma } & \multirow{2}{*}{21} & No & $(0.57) 2$ & \multirow{8}{*}{0.008} \\
\hline & & Yes & (5.5) 19 & \\
\hline \multirow{2}{*}{ High School Diploma } & \multirow{2}{*}{82} & No & $(1.4) 5$ & \\
\hline & & Yes & (22.30) 77 & \\
\hline \multirow{2}{*}{ Bachelor's Degree } & \multirow{2}{*}{185} & No & $(9.20) 32$ & \\
\hline & & Yes & (3.44) 153 & \\
\hline \multirow{2}{*}{ Graduate Degree } & \multirow{2}{*}{57} & No & $(0.57) 2$ & \\
\hline & & Yes & (15.90) 55 & \\
\hline \multicolumn{5}{|l|}{ Occupation } \\
\hline \multirow{2}{*}{ Unemployed } & \multirow{2}{*}{115} & No & $(8.70) 10$ & \multirow{4}{*}{0.191} \\
\hline & & Yes & 105 (91.30) & \\
\hline \multirow{2}{*}{ Employed } & \multirow{2}{*}{229} & No & (13.50) 31 & \\
\hline & & Yes & 198 (86.50) & \\
\hline
\end{tabular}

\section{Discussion}

In this study, the prevalence of sleep disorders was $88 \%$. The prevalence of sleep disorders has been reported in various international studies $(16,17)$. This difference in the prevalence of sleep disorders can be due to cultural differences, the studied society and different instrument and methods of study.

In this study, we did not find a significant association between sleep disorders and gender. This result was in accordance with the results of other studies $(18,19)$.

As with other studies (20-22), this study showed that the use of mass media increased the amount of sleep disorders. There are several hypotheses about the relationship between using mass media and sleep disorders. Firstly, it causes the child to stay awake until midnight. Secondly, the emitted light reduces the secretion of melanin in the eyes, and as a result, impairs sleep. Additionally, the usage of television causes mental conflicts and anxiety (23).

Although the prevalence of sleep disorders was high in children with inappropriate food habit in our study, findings showed that dietary behaviors had no significant effect on sleep disorders. This finding contradicted results of other studies (24), which could be due to different categories of dietary behaviors and different food cultures.

The results of this study showed that a correlative relationship is not present between a mother's occupation and a child's sleep disorders. Such results are quite similar to the findings in other studies $(25,26)$. There was a significant relationship in maternal education and sleep disorders, with children who had mothers of graduate or post-graduate education with the highest prevalence of sleep disorders. This can be attributed to the high sensitivity of mothers with high education and their more attention to their children (26).
This study showed that there is no relationship between the number of siblings and sleep disorders; some studies have reached similar conclusions (26). Yet, other studies have reported a reduction in the prevalence of sleep disorders of children with a few siblings (27).

Fear of sleeping alone was the most common disorder in the studied children, which can be seen in collected data elsewhere $(28,29)$. In other studies, sleep talking was the most commonly reported disorder (30), while, it's prevalence in our study was at $21.4 \%$. Additionally, in a few other studies, waking during nighttime was reported as the most common disorder (31), whereas its prevalence in our study was at $13.9 \%$. Some others studies reported drowsiness during daytime as the most common disorder $(32,33)$, yet, its prevalence in our study was at $14.2 \%$.

Despite the fact that snoring marked the lowest sleep disorder, it is the most common complaint of mothers (34, 5). Snoring can be attributed to sleep-related respiratory disorders, such as Aden tonsillar hypertrophy, which is highly prevalent in the age range of 2-6 years old (35).

\section{Conclusion}

The high prevalence of sleep disorders in our study implicated that these psychological disorders require special attention from pediatricians and pediatric psychiatrists. Therefore, a multi-disciplinary team of pediatricians, pediatric psychiatrists and public health professionals, as well as providing evidence-based clinical guides for specialists and general practitioners should be considered.

\section{Acknowledgment}

We hereby appreciate the support of the authorities in the Education Department of Zanjan Province and the cooperation of our honorable parents. 


\section{Conflict of Interest}

Authors declared no conflict of interests.

\section{References}

1. Soheili H, Yousefichaijan P, Alaghemand A, Sadegi Sedeh B, Tavassoli A, Naziri M. Prevalence of different types of sleep disorders in children with allergic rhinitis. Arak Med J. 2014; 17(1): 39-46.

2. Marcdante KJ, Kliegman RM. Normal Sleep and Pediatric Sleep Disorders. In: Nelson Essentials of Pediatrics. 7th ed. Philadelphia, PA: Elsevier Saunders; 2015. p. 47-50.

3. Sung V, Hiscock H, Sciberras E, Efron D. Sleep problems in children with attention-deficit /hyperactivity disorder: prevalence and the effect on the child and family. Arch Pediatr Adolesc Med. 2008; 162(4): 336-42. [DOI:10.1001/archpedi.162.4.336] [PMID]

4. Owens JA, Dalzell V. Use of the 'BEARS' sleep screening tool in a pediatric residents' continuity clinic: a pilot study. Sleep Med. 2005; 6(1): 63-9. [DOI:10.1016/j.sleep.2004.07.015] [PMID]

5. Simola $\mathrm{P}$, Niskakangas $\mathrm{M}$, Liukkonen $\mathrm{K}$, Virkkula $\mathrm{P}$, Pitkäranta $\mathrm{A}$, Kirjavainen $\mathrm{T}$, et al. Sleep problems and daytime tiredness in Finnish preschool-aged children- a community survey. Child Care Health Dev. 2010; 36(6): 805-11. [DOI:10.1111/j.1365-2214.2010.01112.x] [PMID]

6. Mindell JA, Owens JA. Sleep problems in pediatric practice: clinical issues for the pediatric nurse practitioner. J Pediatr Health Care. 2003; 17(6): 324-31. https://doi.org/10.1016/j.pedhc.2003.09.003 [DOI:10.1016/S0891-5245(03)00215-3]

7. Ozgoli G, Sheikhan Z, Soleimani F, Nasiri M, Mirzai S, Kavoosi F, et al. A Study of effective factors on sleep disorders in 4-6 years old children in Tehran city, Iran. Qom Univ Med Sci J. 2015; 9(5): 50-60.

8. Gau SF, Soong WT. Sleep problems of junior high school students in Taipei. Sleep. 1995; 18(8): 667-73. doi: 10.1093/sleep/18.8.667 [DOI:10.1093/sleep/18.8.667] [PMID]

9. Bapat R, Van Geel V, Vedder P. Socio-economic status, time spending, and sleep duration in Indian children and adolescents. J Child Fam Stud. 2017; 26(1): 80-7. [DOI:10.1007/s10826-016-0557-8] [PMID] [PMCID]

10. Bahremand Z, Hashemian P, Moharreri F, Soltani E. Melatonin effects on sleep disorders in children with attention deficit hyperactivity disorder. Rev in Clin Med. 2014; 1(4): 233-37.

11. Chervin RD, Archbold KH, Panahi P, Pituch KJ. Sleep problems seldom addressed at two general pediatric clinics. $\begin{array}{lll}\text { Pediatrics. } & \text { 2001; } & 107(6):\end{array}$ [DOI:10.1542/peds.107.6.1375] [PMID]

12. Sahin U, Ozturk O, Ozturk M, Songur N, Bircan A, Akkaya A. Habitual snoring in primary school children: prevalence and association with sleep-related disorders and school performance. Med Princ Pract. 2009; 18(6): 458-65. [DOI:10.1159/000235895] [PMID]

13. Alabi BS, Abdulkarim AA, Musa IO, Adegboye O, Aremu SK, Abdur-Rahman LO, et al. Prevalence of snoring and symptoms of sleep disordered breathing among primary school pupils in Ilorin, Nigeria. Int $\mathbf{J}$ Pediatr Otorhinolaryngol. $\quad 2012 ; \quad 76(5)$ : 646-8. [DOI:10.1016/j.ijporl.2012.01.029] [PMID]

14. Jalily M, Barati M, Bashirian S. Using Social Cognitive Theory to Determine Factors Predicting Nutritional Behaviors in Pregnant Women Visiting Health Centers in Tabriz, Iran. J Educ Community Health. 2015; 1(4): 11-21. [DOI:10.20286/jech-010411]

15. Mohammadi M, Amintehran E, Ghaleh-bandi M, Ashrafi MR, Shoaee S, Ghalehbaghi B. Reliability and validity of persian version of "BEARS" pediatric sleep questionnaire. Indian J sleep med. 2008; 3(1): 14-19.

16. Meltzer LJ, Mindell JA. Sleep and sleep disorders in children and adolescents. Psychiatr Clin North Am. 2006; 29(4): 1059-76. [DOI:10.1016/i.psc.2006.08.004] [PMID]

17. Owens J. Classification and epidemiology of childhood sleep disorders. Prim Care. 2008; 35(3): 533-46. [DOI:10.1016/j.pop.2008.06.003] [PMID]

18. Mindell JA, Owens JA. A clinical guide to pediatric sleep: diagnosis and management of sleep problems. 3rd ed. Philadelphia: Wolters Kluwer; 2015. 102.

19. Kryger M, Roth T, Dement WC. Principles and Practice of Sleep Medicine. 6th ed. Philadelphia: Elsevier; 2017. 21.

20. Perkinson-Gloor N, Lemola S, Grob A. Sleep duration, positive attitude toward life, and academic achievement: the role of daytime tiredness, behavioral persistence, and school start times. J Adolesc 2013; 36(2): 311-8. [DOI:10.1016/j.adolescence.2012.11.008] [PMID]

21. Lemola S, Schwarz B, Siffert A. Interparental conflict and early adolescents' aggression: is irregular sleep a vulnerability factor?. J Adolesc. 2012; 35(1): 97-105. [DOI:10.1016/j.adolescence.2011.06.001] [PMID]

22. Cain N, Gradisar M. Electronic media use and sleep in school-aged children and adolescents: A review. Sleep Med. 2010; 11(8): 735-42. [DOI:10.1016/j.sleep.2010.02.006] [PMID]

23. Shochat T. Impact of lifestyle and technology developments on sleep. Nat Sci Sleep. 2012; 4: 19-31. [DOI:10.2147/NSS.S18891] [PMID] [PMCID]

24. Garaulet M, Ortega FB, Ruiz JR, Rey-López JP, Béghin L, Manios Y, et al. Short sleep duration is associated with increased obesity markers in European adolescents: effect of physical activity and dietary habits. The HELENA study. Int J Obes (Lond). 2011; 35(10): 1308-17. [DOI:10.1038/ijo.2011.149] [PMID] 
25. Ozgoli G, Sheikhan Z, Soleimani F, S Mirzaee, P Janatiataee , T Ziaie, et al. Prevalence of Sleep Disorders and its Related Factors Among Preschool Children. J Health Care. 2015; 17(3): 198-206.

26. Panaghi L, Kafashi A, Seraji M. Epidemiology of sleep disorders in elementary school students in Tehran. Andisheh \& raftar J. 2004; 10(1): 50-8.

27. Smedje H, Broman JE, Hetta J. Parents' report of disturbed sleep in 5-7-year-old Swedish children. Acta Paediatr. 1999; 88(8): 858-65. https://doi.org/10.1080/08035259950168793 [DOI:10.1111/j.1651-2227.1999.tb00062.x] [PMID]

28. Javadi M, Javadi A, Kalantari N, Jaliloghadr S, Mohammad H. Sleep problems among pre-school children in Qazvin, Iran. Malays J Med Sci. 2014; 21(6): 52-6.

29. Liu J, Zhou G, Wang Y, Ai Y, Pinto-Martin J, Liu X. Sleep problems, fatigue and performance in Chinese kindergarten children. J Pediatr. 2012: 161(3): 520-5. [DOI:10.1016/i.jpeds.2012.03.018] [PMID] [PMCID]

30. Blunden S. Lushington K., Lorenzen B, Ooi T, Fung F, Kennedy D. Are sleep problem under-recognized in general practice? Arch Dis Child. 2004; 89(8): 708-12. [DOI:10.1136/adc.2003.027011] [PMID] [PMCID]
31. Liu X, Zhao Z, Jia C, Buysse DJ. Sleep patterns and problems among Chinese adolescents. Pediatrics. 2008; 121(6): 1165-73. doi: 10.1542/peds.2007-1464. [DOI:10.1542/peds.2007-1464] [PMID]

32. Jalilolghadr SH, Hashemi F, Jahanihashemi H, Yazdi Z, Alimoradi F, Javadi M. Association of sleep disturbances with TV and satellite watching and video games playing in 14-17 years old high school students of Qazvin. Qazvin Univ Med Sci J. 2017; 21(2): 31-40.

33. Amintehran E, Ghalehbaghi B, Asghari A, et al. High Prevalence of Sleep Problems in School- and Preschoolaged Children in Tehran: a Population Based Study. Iran J Pediatr. 2013: 23(1): 45-52.

34. Mohammadi S, Kazemzadeh M. Sleep Problems among PreSchool Children in Hamadan, Iran. Sleep Med Dis Int J. 2017; 1(2): 27-30 [DOI:10.15406/smdij.2017.01.00006]

35. Meltzer LJ, Johnson C, Crosette J, Ramos M, Mindell JA. Prevalence of diagnosed sleep disorders in pediatric primary care practices. Pediatrics. 2010; 125(6): 1410-18. [DOI:10.1542/peds.2009-2725] [PMID] [PMCID]

\section{How to Cite This Article:}

Torabi Z, Mansouri A, Armani A, Khederlou H. Sleep Disorders in Children of Zanjan City (Northwest, Iran) Kindergartens. J Adv Med Biomed Res. 2018; 26 (118) :15-20

Download citation:

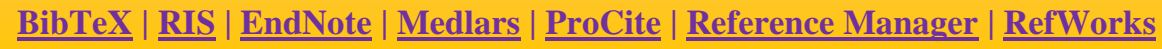

Send citation to:

Mendeley 2 Zotero $\underline{\text { (0) RefWorks RefWorks }}$ 